\title{
Comparison of Stainless Steel and Nickel \\ Titanium Coil Springs Effects on the Space Closure Rate (In Vitro Study)
}

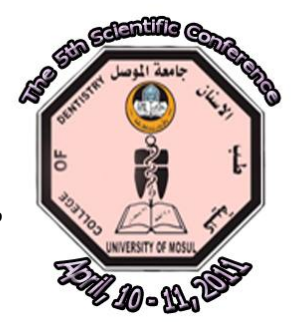

\begin{abstract}
Aim of the Study: To compare the effects of stainless steel and nickel-titanium closed coil springs with the use of Roth bracket type and different arch wires on the amount of space closure during canine retraction in a Typodont simulation system. Material and Methods: Typodont system with Class II division 1 wax form and set of metal teeth, with Roth stainless steel brackets $(0.022 \times 0.030$ inch $)$ slot dimension. Eighty stainless steel readymade (Bonwill-Hawley arch form) arch wires divided in to two groups according to the size $(0.019 \times 0.025$ inch and 0.020 inch $), 40$ for each size. Forty stainless steel and 40 nickel-titanium closed coil springs with force $200 \mathrm{gm}$. The distance between the distal wing of canine's bracket and the mesial end of second molar's tube was $(31 \mathrm{~mm})$ which is the available space. Results: There was a significant difference in the rate of space closure between the two types of arch wires and between nickel titanium and stainless steel closing coil springs. Discussion: The rate of space closure significantly is greater with nickel-titanium closed coil spring. Nickel-titanium closed coil spring produce more sustained light continuous force. Conclusion: Nickeltitanium closed coil spring is an efficient material for canine retraction and space closure even with different wire sizes.
\end{abstract}

Asst Prof Dr Fadhil Y Jasim (BDS, CES, DSO); Asst Lect Wafaa Gh Al-Shahery (BDS, MSc)

Department of Pedodontics, Orthodontics and Preventive Dentistry, Dentistry College, Mosul University

Key words: Fixed appliance, canine retraction, closing coil spring.

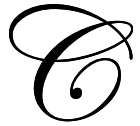

anine retraction is one of the basic techniques in orthodontic treatment. ${ }^{(1)}$ As space closure is a routine procedure in orthodontic practice, researchers have always been interested in determining efficient methods of retracting canines. ${ }^{(2)}$ In broad classification canines can be retracted by frictional (sliding) and non-frictional (closing loop) mechanics. ${ }^{(3,4)}$ Frictional mechanics is the sliding of a tooth along an arch wire by application of a force. ${ }^{(5,6)}$

Over the years, a variety of materials have been used to close spaces between teeth. ${ }^{(7)}$ These include elastic modules of various sorts, elastomeric chain, and stainless steel and nickel titanium springs. ${ }^{(8)}$ Among orthodontic alloys, nickel-titanium alloy had attracted many considerations because of two unique properties (shape memory and low modulus of elasticity). ${ }^{(9)}$ Manufacturers produce nickel titanium springs for dental movements and they believed that the ideal force is produced by these coils. ${ }^{(10)}$

A Typodont simulation system can be used in orthodontics practice to show possible effects of using variable factors on canine position and rate of movement during sliding mechanics using standard edgewise mechanics. 


\section{MATERIALS AND METHODS}

All the study was conducted using Typodont model, with wax form Class II division 1, a set of maxillary metal teeth (all teeth except first premolars and third molars). The Typodont was prepared, for preadjusted Roth stainless steel brackets of maxillary anterior segment and second premolar tooth with $0.022 \times 0.030$ inch slot dimension bracket (Ultratrim Roth brackets, Dentarum, Germany) ( 8 sets) with four preadjusted upper first and second molar bands. All the teeth were well aligned and leveled. ${ }^{(11)}$ An acrylic block was fabricated in to which the four anterior teeth were processed, ${ }^{(12)}$ the acrylic bite plane also was extended in such a way that the second molars can be involved to make them immobile, leaving canine, second premolar and first molar free from acrylic coverage to facilitate sliding movement. Stainless steel arch wires divided to two groups according to the size $(0.019 \times 0.025 "$ and $0.020 ") 40$ for each size and the arch wires are ligated to the brackets by two methods elastic ligatures and by preformed stainless steel ligatures $(0.010$ "). The canine slides along the arch wire with stainless steel $(20 \mathrm{~mm})$ and nickel-titanium (12 mm) closed coil springs (Figure 1) with force $200 \mathrm{gm}$ using tension gauge to measure the delivered force. ${ }^{(13)}$ The distance between the distal wing of canine's bracket and the mesial end of second molar's tube was $(31 \mathrm{~mm})$. This distance is considered as the available space. This distance was measured by digital vernia. ${ }^{(8,14)}$

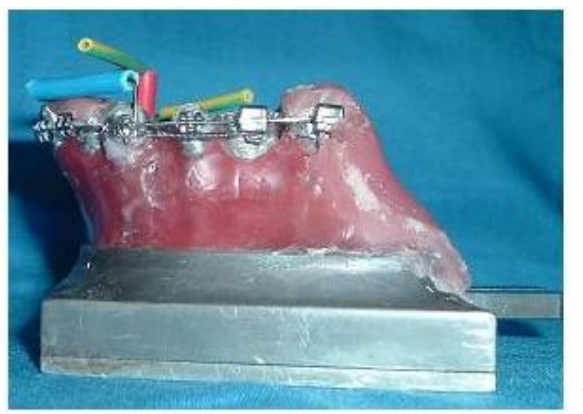

Figure (1): Closed coil spring

between the canine bracket and the hook at the first molar band.

Rate of space closure is measured after each method of canine movement by immersing the Typodont in the water bath with temperature of about $54{ }^{\circ} \mathrm{C}$ for 5 minutes, where again the distance between the distal wing of canine's bracket and the mesial end of second molar's tube is measured $^{(15)}$ using digital vernia. This distance is considered as the remaining space, therefore:

Rate of space closure $=$ Available space - Remaining space.

The data were analyzed using Statistical Package for Social Sciences (SPSS) program version 11.5 to perform descriptive analyses. Student's t-test at level of 0.05 was used to locate the significance.

\section{RESULTS}

The descriptive statistics that include mean, standard deviations, minimum, maximum values of rate of space closure are listed in Table (1).

The findings of the present study showed that the higher mean is for Roth bracket with 0.020 inch stainless steel arch wire using nickel-titanium closed coil spring as retraction method and elastomeric module for ligation while $0.019 \times 0.025$ inch stainless steel arch wire using stainless steel closed coil spring for retraction and stainless steel ligature showed the lowest mean for space closure. The remaining methods distributed on statistical levels between the higher and lower level of mean. 
Table (1): Descriptive analysis (mean, standard deviations, minimum and maximum values of space closure measurement).

\begin{tabular}{|c|c|c|c|c|c|c|c|}
\hline $\begin{array}{c}\text { Bracket } \\
\text { Type }\end{array}$ & $\begin{array}{l}\text { Arch } \\
\text { Wire }\end{array}$ & $\begin{array}{l}\text { Method of } \\
\text { Retraction }\end{array}$ & $\begin{array}{c}\text { Ligature } \\
\text { Type }\end{array}$ & Min. & Max. & Mean & \pm SD \\
\hline \multirow{8}{*}{$\begin{array}{c}\text { Roth } \\
\text { 0.022”' } \\
\text { Stainless } \\
\text { Steel }\end{array}$} & \multirow{4}{*}{$0.020 "$} & Nickel-titanium & Elastic & 4.81 & 6.64 & 5.5730 & 0.49133 \\
\hline & & Spring & Stainless Steel & 3.50 & 6.50 & 5.3600 & 1.0713 \\
\hline & & Stainless Steel & Elastic & 1.63 & 2.98 & 2.3630 & 0.40800 \\
\hline & & Spring & Stainless Steel & 0.80 & 3.00 & 2.3800 & 0.74506 \\
\hline & \multirow{4}{*}{$\begin{array}{c}0.019 \\
\times \\
0.025 \%\end{array}$} & Nickel-titanium & Elastic & 3.00 & 7.00 & 5.0300 & 1.06359 \\
\hline & & Spring & Stainless Steel & 0.50 & 5.00 & 3.8000 & 1.31656 \\
\hline & & Stainless Steel & Elastic & 1.00 & 2.60 & 1.9590 & 0.60510 \\
\hline & & Spring & Stainless Steel & 1.00 & 3.00 & 1.9000 & 0.56765 \\
\hline
\end{tabular}

Min.: Minimum, Max.: Maximum, Measurement unit in mm.

Student's t-test (Table 2 and Figure 2) showed significant difference of the value of Rate of space closure at $(\mathrm{p} \leq 0.05)$ between the two types of retraction springs. In both types of arch wires and ligatures, nickel-titanium closed coil springs showed the higher mean value for Rate of space closure, while the stainless steel closed coil spring showed the lower mean value. In Table (3) and Figure (3) Student's t-test showed significant difference of the value of Rate of space closure at $(p \leq 0.05)$ between the two types of Arch wires. In both types of retraction methods and ligatures. 0.020inch showed the higher mean value for rate of space closure, while $0.019 \times 0.025$ inch arch wire showed the lower mean value. In Table (4) and Figure (4) Student's t-test showed no significant difference of the value of Rate of space closure at $(p \leq 0.05)$ between the two types of ligatures.

Table (2): Comparison of space closure rate between two types of retraction springs.

\begin{tabular}{ccccccc}
\hline Spring Type & No. & Mean & $\mathbf{\pm}$ SD & t-value & d.f & $\boldsymbol{p}$-value \\
\hline Nickel-titanium & 40 & 4.4348 & 1.38518 & & & \\
\cline { 1 - 4 } Stainless Steel & 40 & 1.8491 & 0.72795 & & & $0.000^{*}$ \\
\hline
\end{tabular}

* significant difference existed at $p \leq 0.05$, Measurement unit in $\mathrm{mm}$.

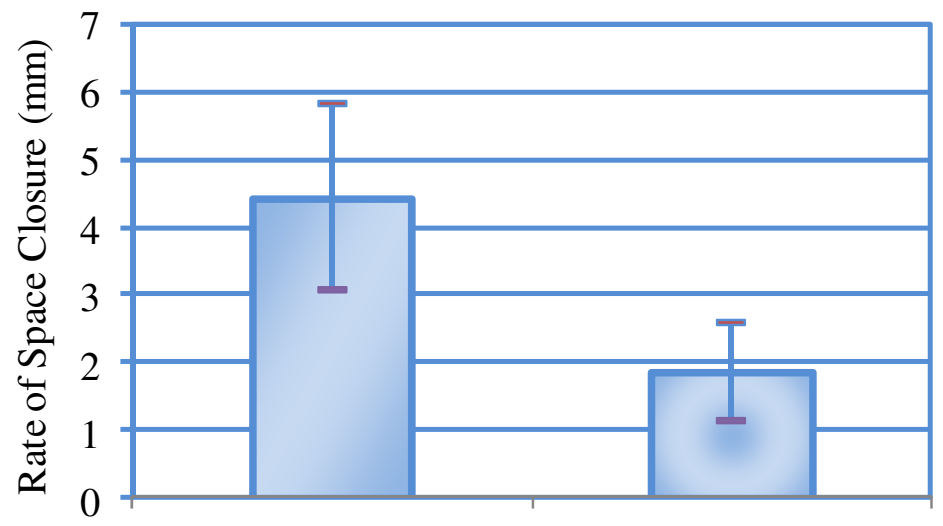

Nickel Titanium Spring Stainless Steel Spring

Figure (2): Comparison of space closure between nickel-titanium and stainless steel closed coil springs.

Journal of the $5^{\text {th }}$ Scientific Conference of Dentistry College, Apr. 2011 
Table (3): Comparison of space closure rate between two types of arch wires.

\begin{tabular}{|c|c|c|c|c|c|c|}
\hline Arch Wire Size & No. & Mean & \pm SD & t-value & d.f & $p$-value \\
\hline $0.019 \times 0.025 "$ & 40 & 2.7961 & 1.62846 & \multirow{2}{*}{-2.616} & \multirow{2}{*}{158} & \multirow{2}{*}{$0.010^{*}$} \\
\hline $0.020 "$ & 40 & 3.4877 & 1.71452 & & & \\
\hline
\end{tabular}

* significant difference existed at $p \leq 0.05$, Measurement unit in $\mathrm{mm}$.

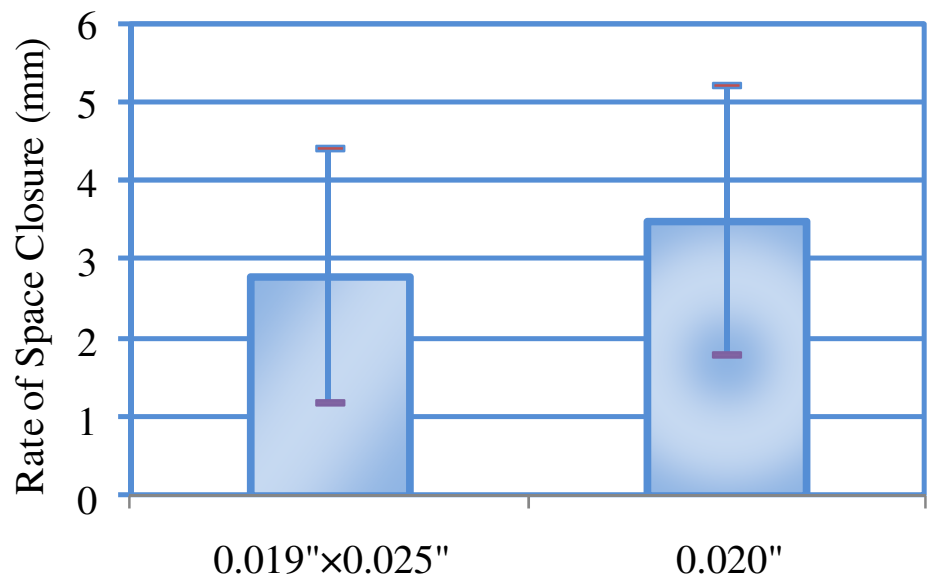

Figure (3): Comparison of rate of space closure between round (0.020") and rectangular $(0.019 " \times 0.025 ")$ stainless steel arch wires.

Table (4): Comparison of space closure rate between two types of ligatures.

\begin{tabular}{ccccccc}
\hline Ligature Type & No. & Mean & $\mathbf{\pm}$ SD & t-value & d.f & $\boldsymbol{p}$-value \\
\hline Elastic & 40 & 3.3418 & 1.73646 & & & 0.138 \\
\cline { 1 - 4 } Stainless Steel & 40 & 2.9421 & 1.65454 & & &
\end{tabular}

Measurement unit in $\mathrm{mm}$.

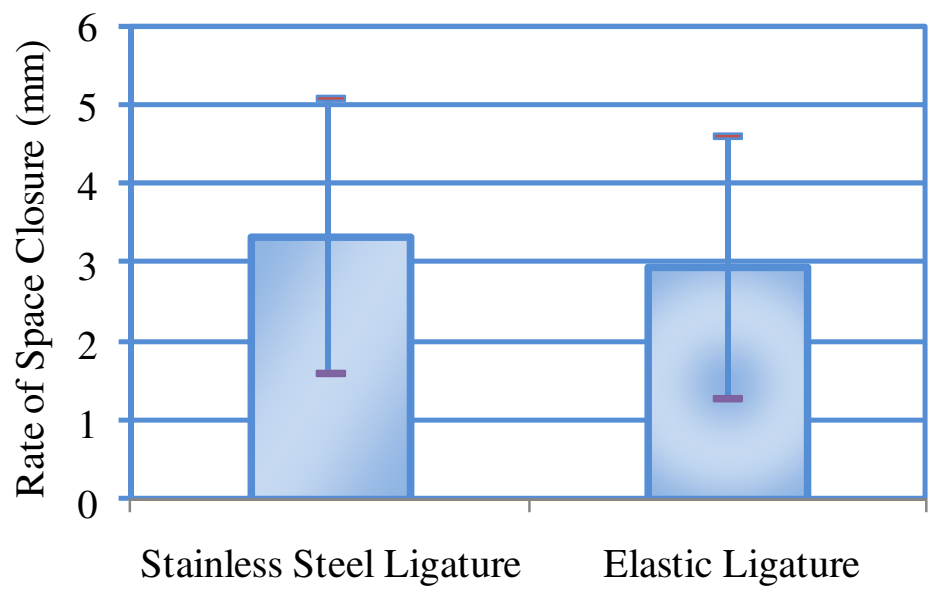

Figure (3): Comparison of rate of space closure between stainless steel and elastic ligatures used. 


\section{DISCUSSION}

The rate of space closure significantly is greater with nickel-titanium closed coil spring, unlike the stainless steel closed coil spring which produce high forces during unloading that decay rapidly as the extension was reduced while the nickel-titanium closed coil spring produce more sustained light continuous force, ${ }^{(16)}$ the rate of space closure with round arch wire was greater than rectangular arch wire, rectangular wire generally shows higher values of friction than the round wires, because there is a larger contact area between slot and wire surfaces ${ }^{(17)}$ where the round wire makes only point contact with a bracket-slot edge. ${ }^{(18)}$

The rate of space closure is not affected by the application of different types of ligature (stainless steel ligature and elastomeric ligature) no significant difference in rate of space closure.

Because there is no difference in the frictional resistance between elastomeric and stainless steel ligation. ${ }^{(18)}$

\section{CONCLUSIONS}

The best combination for higher rate of space closure during canine retraction is the use of Roth bracket with 0.020 inch stainless steel arch wire using nickel-titanium closed coil spring as retraction method.

\section{REFERENCES}

1. Kojima Y, Mizuno T, Umemura S, Fukui H. A numerical simulation of orthodontic tooth movement produced by a canine retraction spring. Dent Mater J. 2007; 26(4): 561-567.

2. Hayashi K, Uechi J, Murata M, Mizoguchi I. Comparison of maxillary canine retraction with a sliding mechanic and a retraction spring: A three-dimensional analysis based on a mid-palatal implant. Eur J Orthod. 2004; 26: 585-589.

3. Choy K, Pae E, Kim K, Park Y, Burstone C. Controlled space closure with a statically determinate retraction system. Angle Orthod. 2002; 72(3): 191-198.

4. Nishio C, da Motta A, Elias C, Much J. In vitro evaluation of frictional forces between archwires and ceramic brackets. Am J Orthod Dentofac Orthop. 2004; 25(1): 56-64.

5. Huffman DJ, Way DCA. Clinical evaluation of tooth movement along arch wires of two different sizes. Am $J$ Orthop Dentofac Orthop. 1983; 83(6): 453-459.

6. Cacciafesta V, Francesca M, Ricciardi A, Scribante A, Klersy C, Auricchio F. Evaluation of friction of stainless steel esthetic self-ligating bracket in various bracket-arch wire combinations. Am J Orthod Dentofac Orthop. 2003; 124(4): 395-402.

7. Chudasama D, Jerrold L. A clinician's guide to space closure using nickel titanium coil spring. Orthod Products. 2009: 1-4.

8. Dixon V, Read MJF, O'Brien KD, Worthington HV, Mandall NA. A randomized clinical trial to compare three methods of orthodontic space closure. J Orthod. 2002; 29(1): 31-36.

9. Alavi Sh, Yaghchie M. Force characteristics of nickel titanium coil springs (3M, GAC, RMO). Dent Res $J$. 2006; 3(2): 77-83.

10. Proffit WR, Fields HW, Ackerman JL, Baily L'TJ, Camilla Tulloch JF. Contemporary Orthodontics. $3^{\text {rd }}$ ed. Mosby Co. St Louis. 2000; Pp: 338-342, 350, 353, 567-577.

11. Eliades T, Zinelis S, Eliades G, Athanasios AE. Nickel content of as-received, retrieved and recycled stainless steel brackets. Am J Orthod Dentofac Orthop. 2002; 122: 217-220.

12. Hoeve AT, Mulie RM, Brandt S. Technique modifications to achieve intrusion of the maxillary anterior segment. J Clin Orthod. 1977; 11(3): 174-198.

13. Quinn RS, Yoshikawa DK. A reassessment of force magnitude in orthodontics. Am J Orthod Dentofac Orthop. $1985 ; 88: 136-144$.

14. McDonald JL, Shofer FS, Chafari J. Effect of molar rotation on arch length. Clin Orthod Res. 2001; 4(2): 79.

15. Sonis AL. Comparison of nickel-titanium coil springs vs. elastics in canine retraction. J Clin Orthod. 1994; 28(5): 293-295.

16. Von Fraunhofer JA, Bonds PW, Johnson BE. Force generation by orthodontic coil springs. Angle Orthod. 1993; 63(2): 145-148.

Journal of the $5^{\text {th }}$ Scientific Conference of Dentistry College, Apr. 2011 


\section{Jasim FY, Al-Shahery WGh}

17. Smith DV, Rossouw P, Watson P. Quantified simulation of canine retraction: Evaluation of frictional resistance. Semin Orthod. 2003; 9(4): 262-280.

18. Frank CA, Nikolai RJ. A comparative study of frictional resistances between orthodontic bracket and arch wire. Am J Orthod. 1980; 78(6): 593-609. 